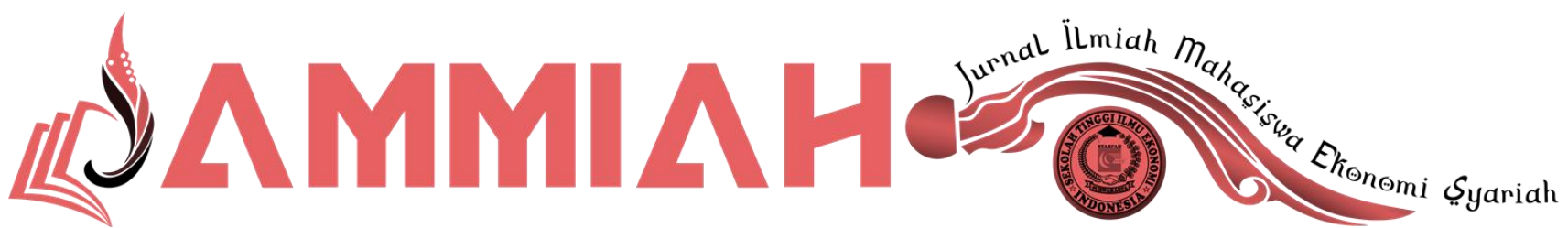

Volume 1 Nomor 1, Maret 2021

DOI: https://doi.org/10.37726/

\section{Sistem Pesanan Dalam Proses Embroidery di PT. Metro Pearl Indonesia}

\author{
Kartika Rahmawati \\ PT. Metro Preal Indonesia \\ kartikarahma@gmail.com
}

\begin{abstract}
ABSTRAK
Konsep jual beli pesanan tanpa di sadari sering di lakukan di perusahaanperusahaan besar yang melakukan transaksi jual beli antara pihak satu dengan pihak lain, konsep ini biasanya di terapkan dalam proses pemesanan barang yang di pesan konsumen kepada produsen sesuai dengan keinginannya, dalam proses jual beli pesanan ini perusahaan sama-sama saling di untungkan. Tujuan penelitian ini untuk mengetahui system jual beli pesanan dalam proses embroidery di PT. Metro Pearl Indonesia. Hasil Penelitian ini adalah sebuah proses pesanan di perusahaan memang membutuhkan proses yang cukup Panjang, dikarenakan ada aturan-aturan yang mengikat yang harus dipatuhi dan dilaksanakan dalam sebuah proses di dalam perusahaan, agar tidak terjadinya kesalahan-kesalahan dan terpenuhinya sebuah standar kerja yang telah ditetapkan.
\end{abstract}

Kata kunci : Jual-Beli, Pesanan, Sistem, Perusahhan

\section{ABSTRACT}

The concept of buying and selling orders without realizing it is often done in large companies that carry out buying and selling transactions between one party and another, this concept is usually applied in the process of ordering goods that consumers order to producers according to their wishes. In the process of buying and selling this order, the company is mutually profitable. This research will focus on the actual process in buying and selling orders according to the implementation 
that occurs in the place under study. That an order process in a company does require a fairly long process, because there are binding rules that must be obeyed and implemented in a process within the company, so that mistakes do not occur and the fulfillment of a predetermined work standard.

Keywords : Buy-Sell, Orders, Systems, Companies

\section{PENDAHULUAN}

Fenomena jual beli dalam kehidupan sehari-hari merupakan fenomena yang menjadi kebiasan di masyarakat. Masyarakat indonesia khususnya banyak sekali yang berprofesi sebagi pedagang. Jual beli di atur juga dalam syariat islam. Jual beli terdiri dari dua macam yaitu jual beli tunai dan jual beli secara tangguh. Jual beli secara tangguh pun terbagi menjadi beberapa macam yaitu jual beli murabahah, jual beli salam, dan jual beli dalam bentuk pesanan. ${ }^{1}$

Konsep jual beli pesanan tanpa di sadari sering di lakukan di perusahaanperusahaan besar yang melakukan transaksi jual beli antara pihak satu dengan pihak lain, konsep ini biasanya di terapkan dalam proses pemesanan barang yang di pesan konsumen kepada produsen sesuai dengan keinginannya. Dalam proses jual beli pesanan ini perusahaan sama-sama saling di untungkan karena konsumen dapat memiliki barang yang diingingkan dan produsen dapat melakukan mendapatkan keuntungan dengan pihak ketiga untuk memenuhi kebutuhan proses pembuatan pesanan sehingga mendapatkan banyak relasi kerja. Untuk itu penulis akan mencoba meneliti penerapan konsep pesanan di dalam sebuah perusahaan Penelitian menganai jual beli pesanan sebelumnya juga pernah dilakukan seperti yang di lakukan Rodame Zidni Nabila Fahmy ${ }^{2}$ menjelaskan mengenai tinjauan hukum islam pada praktek jual beli pesanan dijelaskan bahwa ada syarat-syrata dan rukun yang harus ditetapkan sesuai dengan hukum yang berlaku pada Al-quran dan Hadist. Selanjutnya ada pula penelitian yang dilakukan oleh Yulisa Safitri ${ }^{3}$ mengenai tinjauan hukum islam tentang penundaan pembayaran pada system jual beli pesanan dari beberapa hal yang dijelaskan dapat dipahami bahwa antara pihak penjual dan pemesan sudah membuat kesepakatan terkait dengan sistem pembayarannya, yaitu membayar DP atau uang muka terlebih dahulu dan untuk sisanya akan dibayar setelah pesanan yang dibuat selesai dikirim atau berdasarkan kesepakatan, kejujuran dan kepercayaan adalah salah satu hal yang harus dikaitkan

\footnotetext{
${ }^{1}$ Danuprata, Gita. Buku Ajar Manajemen Perbankan Syariah. Salemba Empat, 2013.

${ }^{2}$ Fahmy, Zidni Nabila. Tinjauan hukum Islam terhadap praktik jual beli pesanan (studi kasus di Toko Mebel Barokah Desa Jepon Blora). Diss. UIN Walisongo, 2016.

${ }^{3}$ Safitri, Y. (2019). Tinjauan Hukum Islam Tentang Penundaan Pembayaran Pada Sistem Pesanan Dalam Jual Beli Istishna.
}

JAMMIAH (Jurnal Ilmiah Mahasiswa Ekonomi Syariah), Volume 1, Nomor 1, Maret 2021 
antara kedua belah pihak. Apabila pihak pemesan memang benar-benar mampu untuk membayarnya dan tidak mempunyai kebutuhan mendesak maka itu tidak diperbolehkan Menurut analisis dalam penundaan pembayaran ini tidak sesuai dengan syariat Islam dikarenakan prinsip-prinsip muamalah yang bertentangan. Selanjutnya ada pula penelitian yng dilakukan oleh Baldi Pramana dan Busyra Azheri ${ }^{4}$ mengenai Pelaksanaan Pengikatan Jual Beli Rumah Melalui Sistem Pesan Bangun Berdasarkan hasil penelitian dan pembahasan yang telah Penulis uraikan pada bagian sebelumnya, maka dapat disimpulkan bahwa pelaksanaan pengikatan jual beli rumah antara konsumen dengan pengembang melalui sistem pesan bangun yang dibuat dihadapan Notaris diawali dengan adanya persetujuan jual beli rumah antara konsumen dengan pengembang, hal ini dikarenakan tidak semua orang mampu secara materil dan inmateril memenuhi semua ketentuan tentang aturan jual beli rumah dan bangunan, dimana wajib dilakukan dengan tunai dan nyata. Guna mengatasi situasi tersebut pengembang dan konsumen sepakat menuangkan kehendak /perbuatan / prestiwa hukum yang bebas kedalam pengikatan jual beli rumah (PJB). Tujuan penelitian ini untuk mengetahui system jual beli pesanan dalam proses embroidery di PT. Metro Pearl Indonesia.

\section{TINJAUAN PUSTAKA}

Penelitian mengenai jual beli pesanan memang telah banayk dilakukan seperti yang dilakukan oleh Ahmad Mukhlishin dan Saipudin ${ }^{5}$ Sistem Jual Beli Pupuk Kandang prespektif Imam Syafi'i Dan Imam Hanafi hasil penelitian menunjukan bahawa sisitem peranan hukum menjadi semakin penting dalam rangka mewujudkan tujuan pembangunan sebagaimana telah ditetapkan. fungsi hukum di sini adalah sebagai sarana pembaharuan masyarakat, berarti hukum digunakan untuk mengarahkan masyarakat pada pola-pola tertentu sesuai dengan yang dikehendakinya dengan menciptakan pola-pola baru, jugaberarti mengubah atau menghapus kebiasaan-kebiasaan lama yang sudah tidak sesuai lagi dengan perkembangan jaman. Dua fungsi hukum tersebut merupakan paduan yang serasi untuk menciptakan hukum yang sesuai dengan masyarakat yang sedang membangun, seperti Indonesia Sebagai makhluk sosial manusia mempunyai berbagai macam kebutuhan, terutama kebutuhan ekonomi. Akan tetapi terkadang dalam pemenuhannya terdapat suatu yang bertentangan dengan syar'i, sedangkan

${ }^{4}$ Pramana, Baldi; Azheri, Busyra. Pelaksanaan Pengikatan Jual Beli Rumah Melalui Sistem Pesan Bangun Pada Pt. Pratama Griya Makmur Kabupaten Pasaman Barat. Al Hurriyah: Jurnal Hukum Islam, 2019, 4.1: 10-19.

${ }^{5}$ Mukhlishin, Ahmad; Saipudin, Saipudin. Sistem Jual Beli Pupuk Kandang Prespektif Imam Syafi'i dan Imam Hanafi (Studi di Kampung Sulusuban Kecamatan Seputih Agung). Jurnal mahkamah: Kajian Ilmu Hukum Dan Hukum Islam, 2017, 2.2: 327-350.

JAMMIAH (Jurnal Ilmiah Mahasiswa Ekonomi Syariah), Volume 1, Nomor 1, Maret 2021 
disisi lain hal ini sangat dibutuhkan Ditinjau dari tempat penelitian maka Jenis penelitian yang digunakan dalam penulisan Tesis ini adalah penelitian lapangan (Field risearch) yaitu mempelajari secara intensif tentang latar belakang keadaan sekarang, dan interaksi lingkungan suatu unit sosial, individu, kelompok, lembaga atau masyarakat. Sedangkan jenis metode penelitian yang digunakan ialah penelitian naturalistik/kualitatif, metode ini digunakan untuk meneliti pada tempat yang alamiah, dan peneliti tidak membuat perlakuan, karena peneliti dalam mengumpulkan data bersifat emic, yaitu berdasarkan pandangan dari sumber data, bukan pandangan peneliti.

Lalu ada penelitian yang dilakukan oleh Faisal Hafid Luthfi, Ifa Hanifia Senjiati dan Fahmi Fatwa Rosyadi ${ }^{6}$ mengenai Tinjauan Fikih Muamalah Akad Salam terhadap Jual Beli Pesanan Pasir dan Batu pada Toko Bangunan Sumber Mulya Kejuden Kabupaten Cirebon dijelaskan bahwa bahwa akad salam merupakan jual beli dengan spesifikasi tertentu menggunakan sistem akad pesanan dengan pembayarannya dilakukan di awal atau terlebih dahulu dan barangnya diserahkan kemudian. Masih banyak lagi pendapat yang diungkapkan para pemikir dalam masalah ini, sebagaimana al-Qurthuby, An-Nawawi dan ulama "malikiyah, serta yang lain, mereka ikut andil memberikan sumbangsih pemikiran dalam masalah ini. Fikih Muamalah akad salam adalah salah satu bentuk jual beli dalam islam yang dilakukan oleh penjual dan pembeli. Pembayarannya dilakukan di muka pada saat akad dan barangnya di tangguhkan atau di serahkan kemudian pada waktu yang di tentukan adapun spesiifikasi, macamnya,kualitasnya harus jelas dan di sepakati di awal.Rukun salam adalah penjual dan pembeli, ada objek, ada sighat (ijab dan qabul). Syarat jual beli salam menurut kesepakatan para ulama ada lima, yaitu jenis obyek jual beli salam harus jelas, sifat obyek jual beli salam harus jelas, kadar atau ukuran obyek jual beli salam harus jelas, jangka waktu pemesanan objek jual beli salam harus jelas.

Yang terakhir ada penelitian yang dilakukan oleh Nur Azizah Fauziyyah, Sandi Rizki Febriadi dan Encep Abdul Rojak Tinjauan Fikih Muamalah Akad Istishna terhadap Praktik Jual Beli Pesanan Parcel di Produsen Parcel dijelaskan bahwa Fikih muamalah adalah dasar baik dan buruk menjadi referensi atau acuan pengambilan keputusan individu sebelum melakukan transaksi. Fikih muamalah juga tidak hanya mencakup larangan-larangan normatif, tetapi juga mengarahkan manusia untuk berperilaku jujur dan amanah juga menerapkan prinsip-prinsip fikih

${ }^{6}$ Luthfi, F. H., Senjiati, I. H., \& Rosyadi, F. F. (2020). Tinjauan Fikih Muamalah Akad Salam terhadap Jual Beli Pesanan Pasir dan Batu pada Toko Bangunan Sumber Mulya Kejuden Kabupaten Cirebon. Prosiding Hukum Ekonomi Syariah, 6(2), 426-429.

JAMMIAH (Jurnal Ilmiah Mahasiswa Ekonomi Syariah), Volume 1, Nomor 1, Maret 2021 
muamalah dalam melakukan transaksi. Fikih muamalah secara umum mengatur keperdataan seseorang dengan orang lain dalam persoalan ekonomi yang telah disajikan dalam perspektif Al-Qur'an dan Hadist. akad istishna dalam fikih mumalah dengan demikian tetap mengedepankan prinsip-prinsip fikih muamalah disamping terpenuhinya rukun dan syarat. Dalam bisnis atau jual beli juga harus memposisikan sebagai usaha manusia mencari keridhaan Allah SWT dan tidak semata-mata mencari keuntungan. Akad istishna dalam fikih muamalah diperbolehkan didasarkan pada suatu kebutuhan yang tidak bias didapatkan di pasaran. Mengacu pada pendapat ulama fikih tentang akad istishna tersebut, maka jelaslah bahwa di dalam syariat Islam khususnya pada persoalan muamalah dalam bidang jual beli pesanan terdapat ketentuan-ketentuan yang saling menguntungkan kedua belah pihak, untuk saling adanya keterbukaan serta saling meridhoi antara kedua belah pihak dalam transaksi. Perbedaanya penelitian ini hanya terfokus pada system jual beli pesanan dalam proses embroidery di PT. Metro Pearl Indonesia.

\section{HASIL DAN PEMBAHASAN}

Jual beli dalam bahasa Arabnya disebut dengan al-bay'. Artinya, tukar menukar atau saling menukar. Menurut terminologi adalah "tukar menukar harta atas dasar suka sama suka". Menurut Ibn Qudamah yang dikutip oleh Rahmad Syafei pengertian jual beli adalah "tukar menukar harta untuk saling dijadikan hak milik". Dapat disimpulkan, bahwa pengertian jual beli menurut bisnis syariah adalah tukar menukar barang antara dua orang atau lebih dengan dasar suka sama suka, untuk saling memiliki. Dengan jual beli, penjual berhak memiliki uang secara sah. Pihak pembeli berhak memiliki barang yang dia terima dari penjual. Kepemilikan masingmasing pihak dilindungi oleh hukum.

Praktek jual beli pesanan sudah banyak dilakukan oleh banyak perusahaan seperti yang dilakukan di PT. Metro Pearl Indonesia salah satu nya pada jual beli pesanan dalam proses embroidery, jual beli pesanan ini melibatkan pihak lain lain yang disebut vendor system jual beli pesanan ini merupakan satu proses rangkaian dalam proses pembuatan produk yang dihasilkan oleh perusahaan

Banyak proses yang harus dilakukan dalam jual beli pesanan proses-proses tersebut harus dilalui agar tercapainya sebuah produk. Berikut implementasi (proses) jual beli pesanan di PT. Metro Preal Indonesia :

1. Proses pembuatan kontrak

Proses ini membutuhkan waktu yang cukup lama, dikarekan dalam pembuatan kontrak ini harus mengisi beberapa persyaratan, pembuatan kontrak ini bisa memakan waktu 3- 5 hari kerja sampai kontrak ini di acc dan

JAMMIAH (Jurnal Ilmiah Mahasiswa Ekonomi Syariah), Volume 1, Nomor 1, Maret 2021

http://journal.sties-purwakarta.ac.id/index.php/jammiah/

ISSN: xxxx-xxxx (Media Online) xxxx-xxxx (Media Cetak) 
bisa digunakan untuk pengajuan pengiriman barang ke pihak vendor untuk proses embroidery tersebut, belum lagi kendala yang harus dihadapi saat pengajuaan kontrak yang dibuat harus direvisi karna ada perubahan konsep dan jenis kontrak.

2. Proses pembuatan schedule pengiriman

Setelah proses pengajuan kontrak selesai dan kontrak di ACC kita membuat schedule pengiriman, pembuatan schedule ini berdasarkan tanggal shipdate dan WH prepare 1 minggu sebelum WH prepare kita harus sudah mengirim barang ke pihak vendor. Lama pengerjaan disesuaikan dengan kuantiti po 1 hari output proses embroidey harus mencapai 1200 pasang agar tanggal shipdate terpenuhi dan pembuatan schedule sesuai jadwal

3. Proses cutting sample

Sebelum pengiriaman PO untuk proses embroidery harus terlebih dahulu mengirimkan sample untuk pihak vendor melakukan trial pengiriman sample biasanya hanya 3 pasang dari jumlah keselurahan po.

4. Pengerjaan sample proses embroidery

Setelah pengiriman sample vendor akan melakukan proses embroidery tersebut sesuai dengan pesanan yang sudah disepakati ( model), pengerjaan akan memakan waktu 1 hari karna harus setting mesin, setting pattern dan proses-proses yang sudah ditetapkan oleh SOP.

5. Pengajuan sample ke buyer

Setelah pengerjaan proses embroidery di vendor kita harus melakuakan konfrim ke buyer untuk melihat kualitas apakah sudah sesuai dengan sample yang diberikan dan standart yang ditetapkan, jika standar sudah terpenuhi maka buyer akan acc untuk proses embroidery tersebut.

6. Pengambilan material

Setelah ACC buyer kita bisa mengambil material di warehouse, pengambilan material harus sesuai denagan SOP, agar tidak ada keslahan dalam pengambilan material.

7. Proses cutting PO

Proses ini dilakukan setelah pengambilan matrial, proses ini akan membutuhkan waktu karna proses cutting biasanya akan dilakukan oleh 1 orag, biasanya dalam 1 jam akan menghasilkan 60 pasang hasil cutting.

8. Penghitungan hasil cutting

Kita harus mengitung ulang material hasil cutting agar kuantiti sesuai dengan PO.

9. Pengiriman material hasil cutting ke vendor

JAMMIAH (Jurnal Ilmiah Mahasiswa Ekonomi Syariah), Volume 1, Nomor 1, Maret 2021

http://journal.sties-purwakarta.ac.id/index.php/jammiah/

ISSN: xxxx-xxxx (Media Online) xxxx-xxxx (Media Cetak) 
Pengiriamn ini dilakuakan jika hasil cutting sudah sesuai dengan jumlah PO, barang akan di packing rapih dan diberi visual agar pihak vendor tau bahwa itu adalah po nya , karna biasanya dalam pengiriman embroidery tidak hanya 1 PO saja , tapi ada beberapa PO

10. Pengiriman $P O$ hasil proses embroidery

Setelah pengerjaan PO proses embroidery selesai pihak vendor akan mengirikan barang nya kembli. Kita akan mengecek kuantiti apa sudah sesuai atau belum.

11. Pengecekan QC hasil embroidery

Pengecekan kuantiti selesai maka dilanjutkan dengan proses pengecekan hasil embroidery 1 per satu biasanya saat pengecekan pasti ada material yang NG karna proses embroidery.

12. Proses supply produksi

Hasil dari pengecekan yang dilakuakn oleh QC, akan langsung di supply ke produksi utuk proses selanjutnya agar jadi sebuah produk.

13. Open repro

Dikarenakn pada proses cek QC ada material yg ng setealah proses embroidery maka akan dibukakan repro untuk memenuhi kuantiti PO tersebut karna material NG tidak bisa di supply ke produksi sehingga mengurangi kuantiti po tersebut.

14. Pengiriman repro

Proses repro tidak beda jauh dengan proses $\mathrm{PO}$, dari mulai pengiriman sampai kembalinya repro tersebut dan di supply ke produksi untuk memenuhi kekurangan PO.

15. Proses Claim

Setelah semua po terpenuhi dan supply ke produksi maka proses selanjutnya adalah proses claim kepada pihak vendor karna kita harus membuka repro akbiat dari NG nya proses embroidery ,

16. Proses pembayaran

Sesuai dengan kesepakatan Bersama bahwa prose pembayaran akan dilalukan setelah PO-PO tersebut tealh beres untuk proses embroidery.

Itulah beberapa rangakaian dalam system jual beli pesanan dalam proses embroidery yang dialkuakn di perushaan.

\section{KESIMPULAN}

Bahwa sebuah proses pesanan di perusahaan memang membutuhkan proses yang cukup Panjang, dikarenakan ada aturan-aturan yang mengikat yang harus

JAMMIAH (Jurnal Ilmiah Mahasiswa Ekonomi Syariah), Volume 1, Nomor 1, Maret 2021

http://journal.sties-purwakarta.ac.id/index.php/jammiah/

ISSN: xxxx-xxxx (Media Online) xxxx-xxxx (Media Cetak) 
dipatuhi dan dilaksanakan dalam sebuah proses di dalam perusahaan, agar tidak terjadinya kesalahan-kesalahan dan terpenuhinya sebuah standar kerja yang telah ditetapkan. System yang diterapakan oleh Pt. Metro tealah memenuhi standar kerja yang baik meminimalisir sebuah keslahan kerja dan mentaati SOP yang berlaku dan menjalankan nya dengan baik dan benar.

\section{DAFTAR PUSTAKA}

Danuprata, Gita. Buku Ajar Manajemen Perbankan Syariah. Salemba Empat, 2013.

Fahmy, Zidni Nabila. Tinjauan hukum Islam terhadap praktik jual beli pesanan (studi kasus di Toko Mebel Barokah Desa Jepon Blora). Diss. UIN Walisongo, 2016.

Safitri, Y. (2019). Tinjauan Hukum Islam Tentang Penundaan Pembayaran Pada Sistem Pesanan Dalam Jual Beli Istishna.

Pramana, Baldi; Azheri, Busyra. Pelaksanaan Pengikatan Jual Beli Rumah Melalui

Sistem Pesan Bangun Pada Pt. Pratama Griya Makmur Kabupaten Pasaman Barat. Al Hurriyah: Jurnal Hukum Islam, 2019, 4.1: 10-19.

Mukhlishin, Ahmad; Saipudin, Saipudin. Sistem Jual Beli Pupuk Kandang Prespektif Imam Syafiâ $€^{\mathrm{TM}}$ i dan Imam Hanafi (Studi di Kampung Sulusuban Kecamatan Seputih Agung). Jurnal mahkamah: Kajian Ilmu Hukum Dan Hukum Islam, 2017, 2.2: 327-350.

Luthfi, F. H., Senjiati, I. H., \& Rosyadi, F. F. (2020). Tinjauan Fikih Muamalah Akad Salam terhadap Jual Beli Pesanan Pasir dan Batu pada Toko Bangunan Sumber Mulya Kejuden Kabupaten Cirebon. Prosiding Hukum Ekonomi Syariah. 